\title{
Percepções do ensino de programação em cursos de tecnologia da informação: o que pensam discentes e docentes?
}

\section{Perceptions of the Teaching of Programming in Information Technology Courses: What Do Students and Professors Think?}

\author{
Oscar Pereira de Oliveira Neto ${ }^{1 *}$, Reudismam Rolim de Sousa ${ }^{1}$, Laysa Mabel de Oliveira \\ Fontes $^{1}$
}

\begin{abstract}
RESUMO
As instituições de ensino superior vêm constantemente relatando problemas referentes aos insucessos nas componente curriculares voltadas ao ensino de programação introdutória. Em especial, no curso de Bacharelado em Tecnologia da Informação, da Universidade Federal Rural do Semi-Árido, é comum o reporte de discentes e docentes referentes a essas dificuldades. Essa problemática pode causar diversas dificuldades, tais como a evasão do curso, dificuldade dos discentes em acompanhar disciplinas futuras e a necessidade das instituições em alocar docentes para atender a essas componentes curriculares. Neste sentido, vários estudos vêm sendo desenvolvidos para tratar a temática, no sentido de reduzir esses insucessos e problemáticas envolvidas. Particularmente, neste estudo foi realizada uma pesquisa para identificar as percepções de discentes e docentes sobre o ensino-aprendizagem de programação. Para isso, foram desenvolvidos dois surveys, o primeiro voltado para entender a percepção dos discentes sobre as suas dificuldades e o segundo voltado à visão dos docentes sobre as dificuldades dos discentes. Dos resultados destes surveys foram elencadas as principais intuições/insights para entender o porquê das dificuldades e também direcionar pesquisas futuras para atacar essas dificuldades.
\end{abstract}

Palavras-chave: Programação introdutória; Educação; Survey; Percepções;

\begin{abstract}
Higher education institutions have been constantly reporting problems related to failures in the classes aimed at teaching introductory programming. In particular, in the course of Bachelor Degree in Information Technology at the Federal Rural University of the Semi-Arid Region, is common for students and professors to report on difficulties in these classes. This problem can cause several difficulties, such as evasion from the course, the difficulty for students to follow future classes related to the subject, and the need for institutions to allocate professors to teach these classes. In this sense, several studies have been developed to address the issue, in order to reduce these failures and problems involved. Particularly, in this study, a survey was performed to identify the perceptions of students and teachers about teaching-learning in introductory programming. For this purpose, two surveys were developed, the first aimed at understanding the perception of students about their difficulties and the second aimed to understand the teachers' point of view of the students' difficulties in introductory programming. From the results of these
\end{abstract}

\footnotetext{
${ }^{1}$ Universidade Federal Rural do Semi-Árido. *E-mail: oscarolvrr@gmail.com
} 
surveys, the main intuitions/insights were listed to understand the reasons for the difficulties and also direct future research to attack these difficulties.

Keywords: Introductory programming; Education; Survey; Perceptions;

\section{INTRODUÇÃO}

Ao ingressar em um curso superior na área de computação, mais especificamente, ao cursar disciplinas de programação introdutória, tal como a componente curricular Algoritmos, alguns requisitos importantes para o entendimento do conteúdo acabam sendo exigidos dos alunos, como: interpretação, raciocínio lógico, abstração e a resolução eficiente de problemas (HOLANDA et al., 2019; GOMES, 2008). As disciplinas de programação necessitam de constante prática e resolução de problemas para uma aprendizagem completa, mas são encontradas dificuldades por parte dos alunos, levando a um mau desempenho durante a disciplina, resultando até no aumento da evasão dos cursos (SANTOS et al. 2018; SOUSA, 2020; SOUSA et al. 2020).

Devido a estas dificuldades encontradas, há uma crescente falta de sucesso nas disciplinas de programação introdutória, que, por sua vez, vem motivando o desenvolvimento de metodologias, técnicas e ferramentas para auxiliar o ensino e a aprendizagem nas turmas (HOLANDA et al., 2019; GOMES, 2008).

Diante disso, este trabalho propõe um estudo para identificar as perspectivas de discentes e docentes sobre o ensino-aprendizagem de programação introdutória. Para o desenvolvimento deste estudo, foram realizados dois surveys para: (i) entender as perspectivas dos discentes sobre a temática; e (ii) compreender o que os docentes entendem como fatores que afetam o ensino-aprendizagem.

Dentre os principais resultados, os discentes apontaram que a melhor abordagem para o aprendizado de programação é o estudo em grupo e que a principal dificuldade com os conteúdos estudados em programação introdutória é com as estruturas de repetição. Ademais, os discentes afirmaram que a falta de tempo para se dedicar aos estudos é a principal causa para os insucessos nas componentes curriculares voltadas para programação introdutória. Também foi identificado que os discentes apresentam pouco interesse em buscar conteúdo fora dos trabalhados em sala de aula. 
Os docentes confirmaram que as maiores dificuldades dos discentes são com as estruturas de repetição. Além disso, os docentes apontaram que: (i) a participação dos discentes costuma ser baixa; (ii) a dificuldade dos discentes é alta; (iii) a procura aos docentes para tirar dúvidas fora do horário de aula é baixa; (iv) o empenho em resolver atividades propostas é razoável; e (v) a permanência dos discentes nas aulas é alta.

O estudo está organizado da seguinte forma: na Seção 2, é apresentada a metodologia utilizada para a condução deste estudo; na Seção 3, alguns trabalhos relacionados são apresentados; na Seção 4, são apresentados e discutidos os resultados; por fim, na Seção 5, são apresentadas as considerações finais deste estudo.

\section{METODOLOGIA}

Para responder às questões de pesquisa, utilizou-se como base o processo utilizado na caracterização da experiência dos usuários, denominado de Double Diamond (MORRIS e CRUICKSHANK, 2013). Este processo é definido por quatro etapas para o design completo de um produto. No entanto, como o propósito desta pesquisa era identificar as perspectivas de discentes e docentes sobre o ensino de Algoritmos, foi necessário o uso das duas primeiras etapas, a saber:

- Descoberta: nesta etapa são coletadas as ideias iniciais sobre a temática e a identificação dos envolvidos na temática;

- Definição: nesta etapa é realizada a interpretação (refinamento dos dados) e alinhamento dos principais direcionamentos associados ao tema.

$\mathrm{Na}$ etapa de descoberta foi utilizada uma metodologia de pesquisa do tipo survey. Segundo Mineiro (2021), um survey consiste em um tipo de pesquisa que objetiva elencar características gerais de indivíduos que fazem parte de um grupo.

Como o objetivo desta pesquisa é confrontar as ideias dos discentes e docentes sobre o tema em questão, foram desenvolvidos dois surveys, um com a população dos discentes e o segundo voltado a entender as perspectivas dos docentes.

A pesquisa tem caráter quali-quantitativo, visto que foram utilizadas questões objetivas para entender a inclinação da população para determinado posicionamento e também foram utilizadas questões abertas, em que os participantes poderiam informar pontos não elencados no estudo. 


\section{Planejamento}

Para o desenvolvimento do survey foram aplicados questionários online. Os questionários foram organizados em duas seções principais. A primeira delas relacionada às características gerais dos participantes e a segunda relacionada às principais dificuldades apresentadas pelos discentes e percebidas pelos docentes nos discentes.

No tocante ao questionário do discente, as informações básicas coletadas foram o gênero, idade e período de ingresso na instituição. Por sua vez, as perguntas referentes às dificuldades com o aprendizado de programação estão relacionadas com: i) a melhor forma de se estudar programação; (ii) os conhecimentos sobre programação antes de cursar a disciplina de Algoritmos; (iii) as principais dificuldades para o entendimento de programação; (iv) os conteúdos estudados na disciplina de Algoritmos que os discentes encontram mais dificuldade; (v) a existência de insucessos do discente com trancamento, desistência ou reprovação na disciplina de Algoritmos; e (vi) a busca por conteúdos fora do abordado nas aulas de Algoritmos.

Por sua vez, as informações básicas coletadas no formulário online enviado para os docentes foram gênero, idade e o tempo em que leciona na instituição. Já as perguntas associadas às dificuldades dos discentes foram: (i) quantas vezes o docente havia lecionado a componente Algoritmos; (ii) quais conteúdos abordados o docente observa que os alunos apresentam maiores dificuldades; (iii) como o docente percebe alguns aspectos dos discentes que participam de Algoritmos; e (iv) como o docente avalia o desempenho geral da turma.

As questões quantitativas foram utilizadas para identificar os aspectos mais salientes das percepções de discentes e docentes. Por sua vez, as questões abertas foram utilizadas para coletar características não evidenciadas nos questionários, possibilitando uma visão mais ampla sobre o universo de estudo.

\section{Execução}

O questionário para os discentes foi enviado para aqueles do curso de Bacharelado em Tecnologia da Informação da Universidade Federal Rural do Semi-Árido. Por sua vez, o questionário voltado aos docentes foi enviado para os docentes que ministram ou ministraram a componente curricular de Algoritmos na instituição. 
Após a coleta dos dados, foram utilizadas técnicas para identificar os principais aspectos da experiência dos discentes e docentes com a componente curricular Algoritmos. Ao todo, o questionário dos discentes recebeu 25 respostas e, por sua vez, o formulário dos docentes recebeu 6 respostas.

Na etapa de descoberta elencada pelo método Double Diamond foram desenvolvidos os questionários online. A etapa de definição do método consiste em elencar os principais aspectos que emergem desses dados. Para isso, são utilizadas diferentes técnicas, tais como determinação de parede de insights e determinação dos tops insights.

$\mathrm{Na}$ determinação da parede de insights, os dados são dispostos em um mural (parede) e o pesquisador confronta os dados para descoberta de oportunidades e padrões de resposta.

No que lhe concerne, na determinação das intuições, as percepções são sintetizadas da parede de insights e são determinados os principais aspectos e experiências associadas à população em estudo.

\section{TRABALHOS RELACIONADOS}

Moreira et al. (2018) realizaram um survey com estudantes de cursos de programação introdutória, buscando identificar as causas envolvidas nos insucessos dos estudantes deste contexto. Os autores indicaram que as principais dificuldades dos alunos estão relacionadas (i) ao entendimento da lógica de programação e (ii) no entendimento da sintaxe da linguagem de programação. Também foram estudados os principais temas que os discentes apresentam maiores dificuldades, tendo os discentes indicado como principais dificuldades (i) funções e (ii) estruturas de repetição.

Holanda et al. (2019) realizaram uma revisão sistemática da literatura, objetivando identificar as estratégias que apoiam o ensino-aprendizagem em cursos superiores de temas referentes à programação introdutória. Os artigos foram pesquisados nos 5 anos de estudos da literatura (2014 a 2018) e os artigos foram selecionados dos principais veículos nacionais voltados para educação, sendo eles: (i) Revista Brasileira de Informática na Educação (RBIE); (ii) Revista Novas Tecnologias na Educação (RENOTE); (iii) Workshop sobre Educação em Computação (WEI); (iv) Workshop de Informática na Escola (WIE); e (v) Congresso Brasileiro de Informática na Educação (CBIE). As 
principais questões de pesquisa foram: (i) as principais técnicas e metodologias empregadas para resolver problemas na temática; (ii) as ferramentas de software que costumam ser empregadas; (iii) as categorias de estudos neste contexto; e (iv) aos principais desafios encontrados na área.

Queiroz et al. (2018) realizou um survey para identificar os principais fatores que motivam ou desmotivam os estudantes para o aprendizado de programação introdutória. Eles identificaram que os discentes apresentam dificuldades no entendimento da lógica de programação, bem como em compreender rápido o enunciado da questão. Eles também pontuaram que estudar em grupo, práticas e professores motivados são os principais fatores associados à motivação para o estudo.

Por sua vez, Holanda et al. (2018) perceberam que as dificuldades dos alunos podem estar relacionadas ao ritmo de aprendizagem de cada aluno. Neste sentido, eles propuseram uma intervenção metodológica para auxiliar no aprendizado de programação introdutória. A intervenção metodológica consiste na inclusão de práticas de programação complementares às abordadas em sala de aula, em que são apresentadas descrições da resolução dos problemas e de cenários associados a eles, assim como dicas envoltas na resolução do problema.

\section{RESULTADO E DISCUSSÕES}

Nesta seção os resultados da aplicação do método Double Diamond são apresentados e discutidos. Ao longo das discussões são apresentados os principais insights/intuições descobertos e sintetizados.

\section{Caracterização geral dos discentes}

Primeiramente foram identificadas as características gerais da população de discentes. A maioria dos discentes são do sexo masculino, conforme Figura 1, característica comum nos cursos voltados à tecnologia da informação. 
Figura 1 - Gênero dos participantes

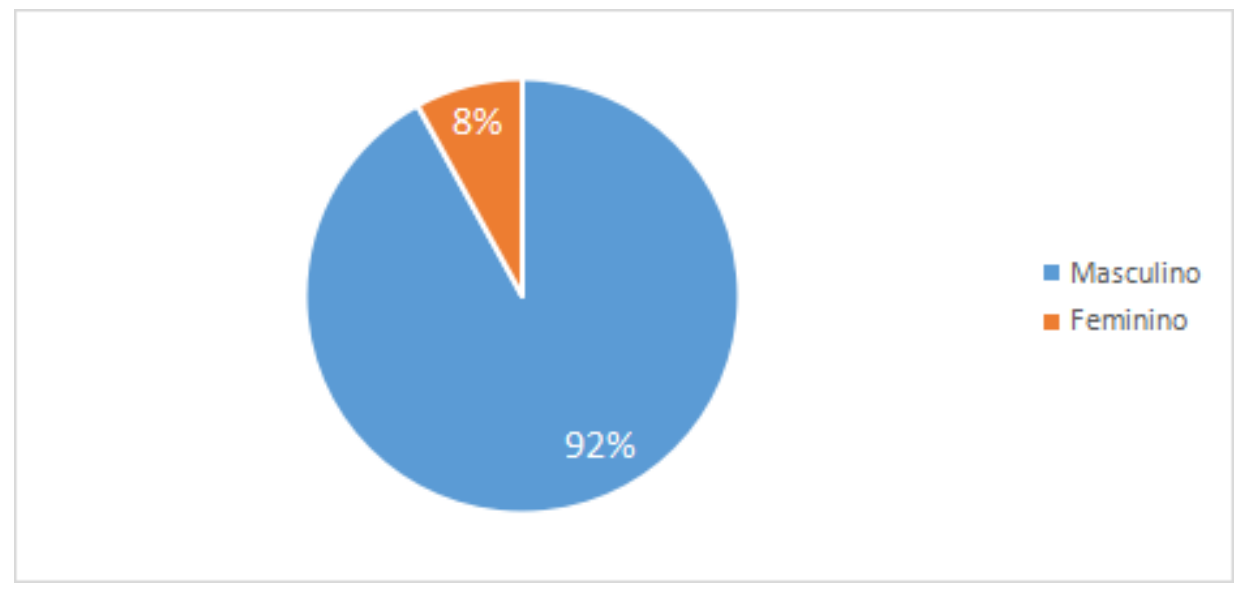

Fonte: Autoria própria

Ademais, os discentes são caracterizados por um público jovem, com faixa etária entre 16 e 30 anos, conforme a Figura 2.

Figura 2 - Idade dos participantes

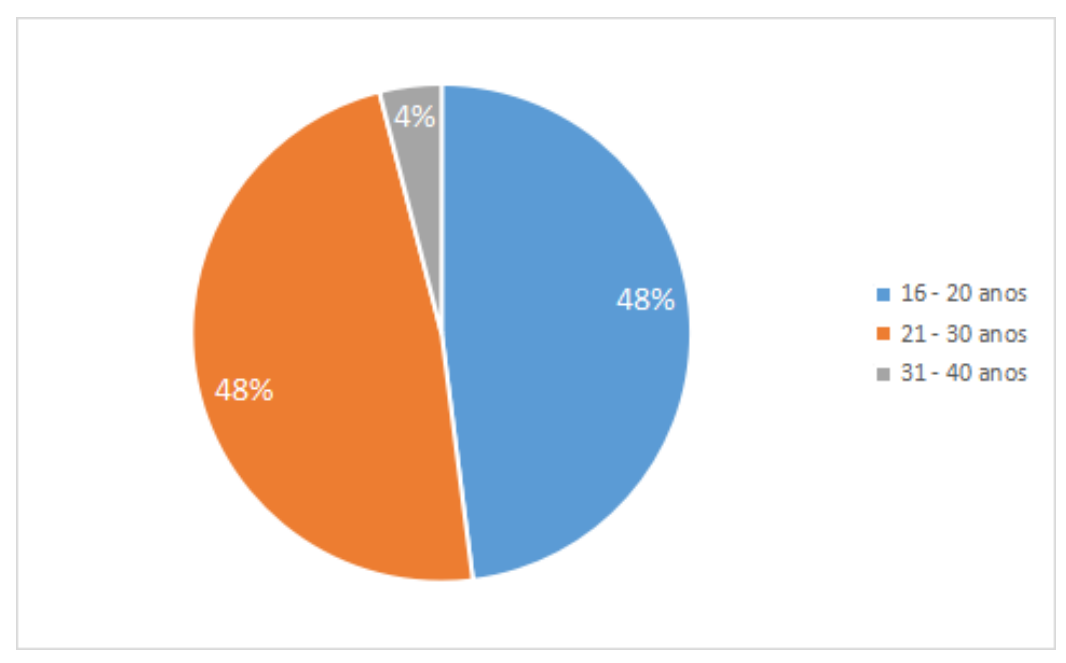

Fonte: Autoria própria

A predominância das respostas são de discentes do semestre 2020.2, como pode ser visto na Figura 3. 
Figura 3 - Semestre letivo dos discentes

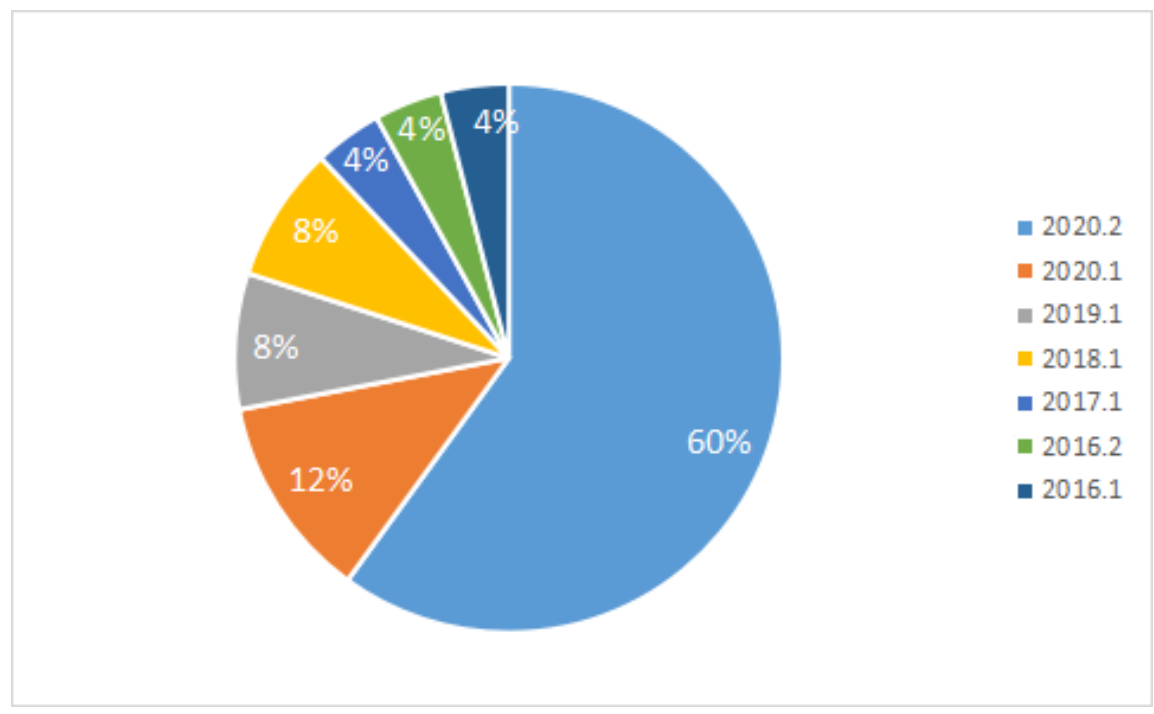

Fonte: Autoria própria

\section{Perspectiva dos discentes sobre o ensino de programação}

No tocante às perspectivas dos discentes sobre o ensino de programação, esta seção apresenta os principais insights.

O estudo em grupo é a principal forma de estudo de interesse dos discentes (44\%), seguido do uso de vídeo-aulas (28\%), conforme Figura 4. Na Tabela 1 são elencados os principais pontos levantados pelos discentes no tocante a melhor forma de estudar.

Figura 4 - Melhor forma de se estudar programação

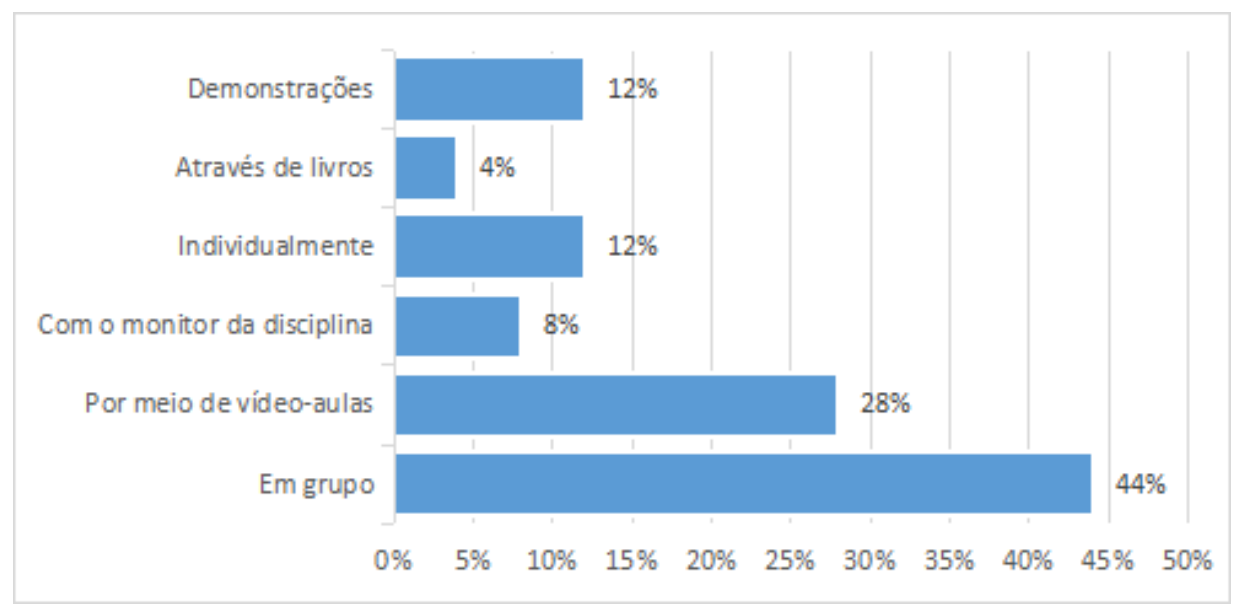

Fonte: Autoria própria 
Tabela 1 - Síntese dos principais pontos levantados pelos discentes no tocante à melhor forma de estudar.

O estudo em grupo facilita o aprendizado.

Antes do ingresso no ensino superior, utilizava PDF de livros. Mas, atualmente no EaD, o auxílio dos monitores está sendo primordial.

O estudo em grupo permite a buscar por várias alternativas para resolver problemas.

A vídeo-aula oferece um bom suporte, visto que ela é pensada e organizada antes de sua gravação e também permite rever as aulas no momento mais apropriado.

O estudo prático ofertado nos encontros de monitoria.

Uma maior variedade de opções permite maiores possibilidades de aprendizagem. $\mathrm{O}$ estudo em grupo facilita o aprendizado, mas a prática é muito importante; a participação em monitorias, o uso vídeo-aulas, jogos e livros também auxilia.

O uso de livros é importante, visto que explicam e mostram exemplos que direcionam o aprendiz a um algoritmo específico, além de mostrar o propósito e o uso de cada elemento da linguagem usada.

Neste sentido, duas intuições principais podem ser extraídas das respostas dos discentes: (i) a maioria prefere estudo em grupo, pois a troca de conhecimentos é maior; e (ii) uma boa percentagem prefere vídeo-aulas, pois é melhor de se concentrar e absorver o conhecimento, e por possuir uma melhor organização do conteúdo.

Uma das justificativas para as dificuldades apresentadas pelos discentes pode estar relacionada à falta de tratamento do tema no ensino básico. A maioria dos estudantes que ingressam não possuem nenhum conhecimento sobre programação, conforme pode ser observado na Figura 5. As principais informações elencadas pelos estudantes neste ponto podem ser consultadas na Tabela 2 . 
Figura 5 - Conhecimentos sobre programação antes de cursar a disciplina de

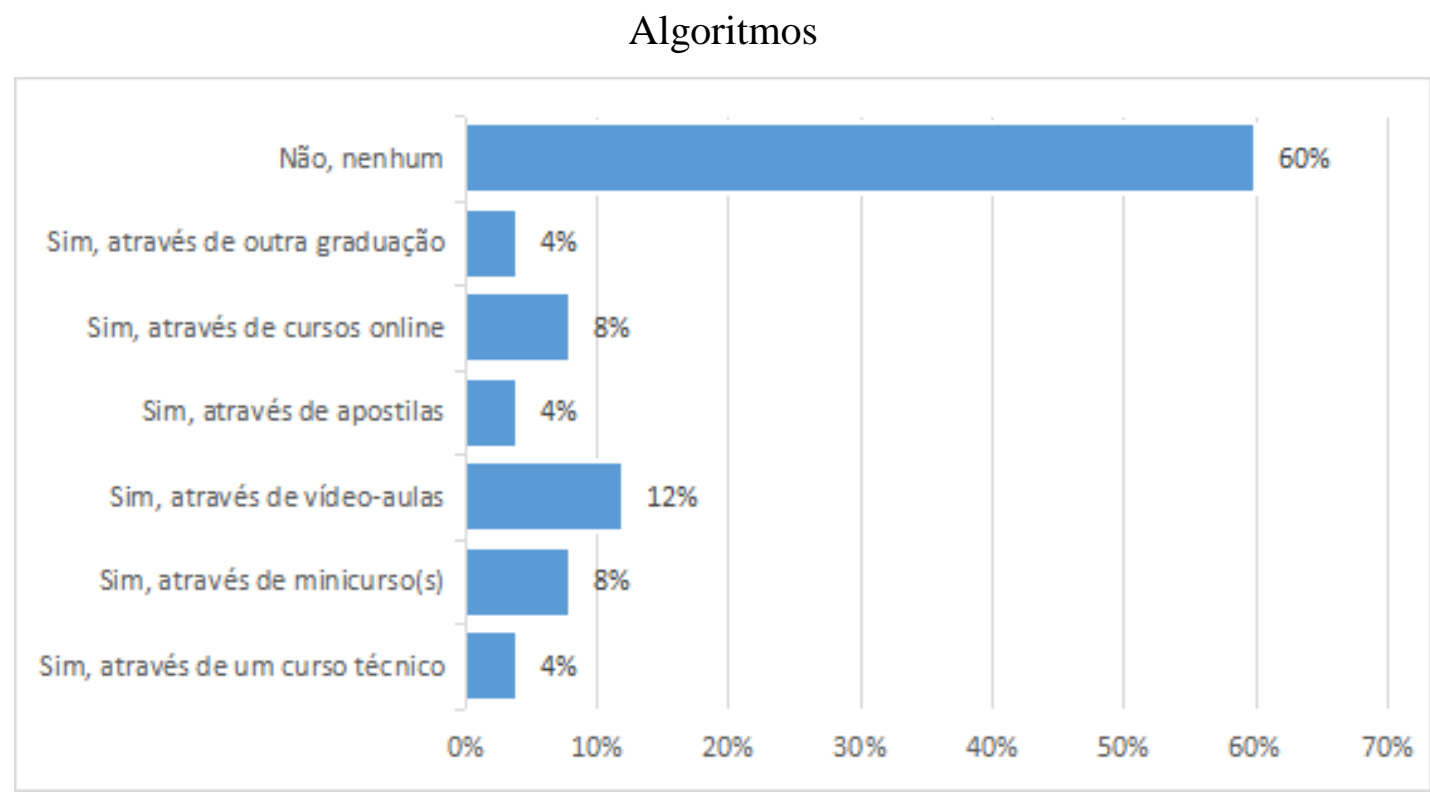

Fonte: Autoria própria

Tabela 2 - Síntese dos principais pontos levantados pelos discentes no tocante aos conhecimentos sobre programação antes de cursar a disciplina de Algoritmos.

Muito pouco conhecimento, mas com uma ideia bem formulada do assunto.

Já tinha visto e pesquisado, mas nunca aprendi.

Não, mas sempre fui curioso em aprender.

Tive contato com vários minicursos de programação online através de apostilas. Cada curso usava uma linguagem diferente. Colaborei no desenvolvimento de um pequeno sistema.

Conhecia um pouco de Python e lógica de programação.

Adquiri conhecimentos por meio de livros.

Não sabia que existia um monte de linhas de código, por trás das telas bonitas.

No tocante a temática desta questão, os principais insights são: (i) a maioria não possuía conhecimento do assunto nem tiveram contato; e (ii) os discentes que tiveram contato foram por conhecidos que trabalham na área, livros, minicursos e cursos técnicos. 
Os discentes tendem a apresentar maiores dificuldades no desenvolvimento da lógica de programação $(60 \%)$ e de entender a sintaxe da linguagem de programação (36\%), conforme Figura 6. Os motivos para as dificuldades apresentadas podem ser vistos na Tabela 3. Estes resultados vão de encontro ao que é apontado pela literatura: Moreira et al. (2018) também identificaram essas mesmas dificuldades como mais preocupantes e Queiroz et al. (2018) pontuaram também a dificuldade no entendimento da lógica para a resolução de problemas como fator preocupante.

Neste sentido, as principais dificuldades dos discentes podem ser sintetizadas em (i) as maiores dificuldades enfrentadas estão relacionadas ao desenvolvimento da lógica de programação e a sintaxe e (ii) a dificuldade em realizar cálculos matemáticos e a falta de tempo para se dedicar foram notórias também.

Figura 6 - Principais dificuldades para o entendimento de programação

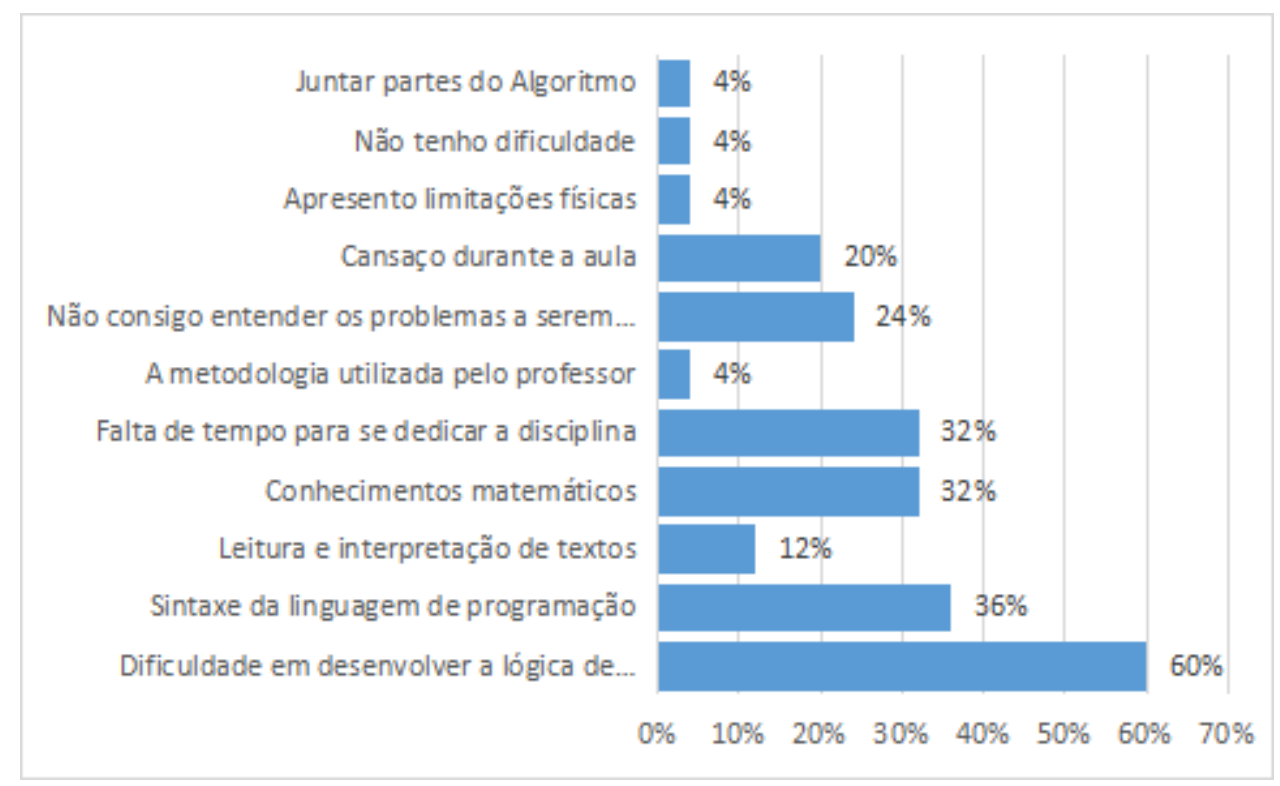

Fonte: Autoria própria

Tabela 3 - Síntese dos principais pontos levantados pelos discentes no tocante às principais dificuldades para o entendimento de programação.

Ausência de tempo devido a outras disciplinas, acabo não tendo tempo para responder os exercícios propostos, mas é dedicado às aulas.

Às vezes, a lógica é bastante simples, mas acaba ficando confuso; porém, uma revisão do conteúdo auxilia no desenvolvimento da solução para o problema. 
$\mathrm{O}$ acumulo de atividades pode dificultar o aprendizado.

A resolução pode não ser a adequada devido a interpretação incorreta do problema.

A dificuldade com a sintaxe da linguagem.

A dificuldade da maioria dos discentes é desenvolver a lógica de programação por ter poucos conhecimentos matemáticos e a compreensão da sintaxe da linguagem de programação.

Referentes aos conteúdos estudados na disciplina de Algoritmos, as maiores dificuldades foram encontradas no tema de estruturas de repetição (40\%) e vetores, matrizes e strings (20\%), conforme pode ser visto na Figura 7. Como fatores para as dificuldades, adicionais aos apontados, os discentes apontaram um comentário referente a dificuldade de se entender as condições de cada estrutura de repetição. Esses resultados vão de encontro com o que aponta a literatura. Moreira et al. (2018) apontaram que as estruturas de repetição são as fontes das maiores dificuldades dos discentes.

Figura 7 - Conteúdos estudados na disciplina de Algoritmos que os discentes apresentam mais dificuldade

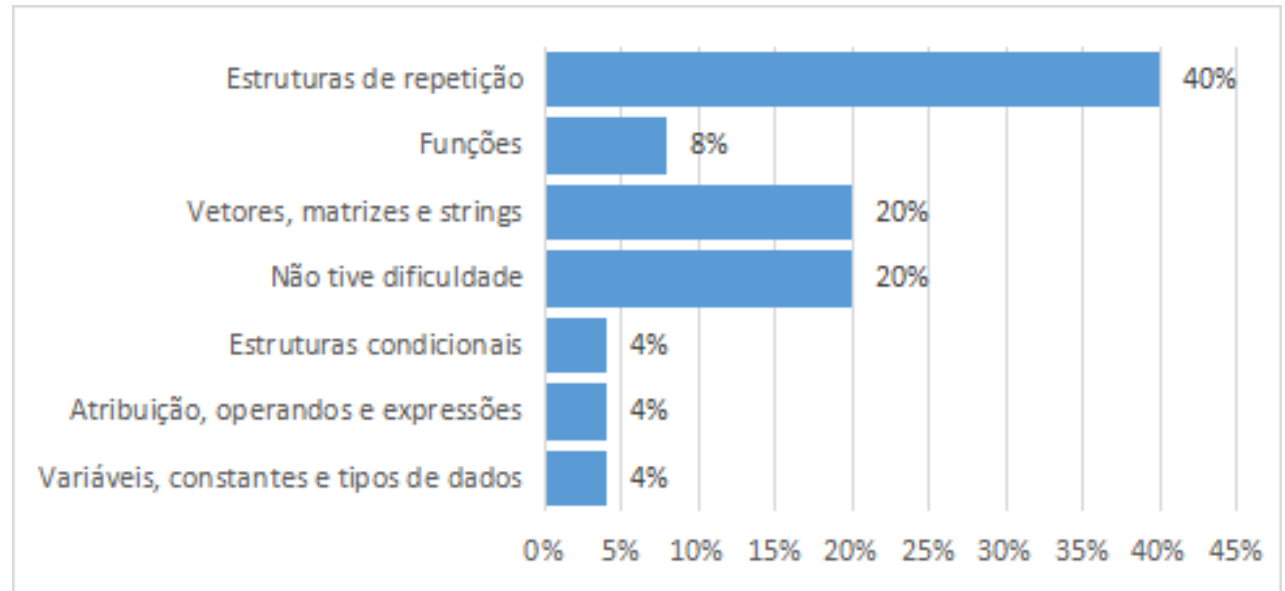

Fonte: Autoria própria

As intuições principais decorrentes dessa questão foram que: (i) estruturas de repetição é o assunto que mais causa dificuldade, seguido de Vetores, Matrizes e Strings; e (ii) as respostas podem ter sido influenciadas pelo período corrente da pesquisa, pois 
até a data da pesquisa o assunto de vetores, matrizes e strings não havia sido lecionado pelos professores.

Os resultados apontam que a maioria dos discentes nunca teve um insucesso na disciplina (80\%), conforme a Figura 8. No entanto, esses dados podem estar influenciados pelos dados correntes, tendo em vista que a maioria (60\%) são provenientes do período corrente, estando participando da componente curricular pela primeira vez.

Figura 8 - Trancamentos, desistências ou reprovações na disciplina de Algoritmos em algum período

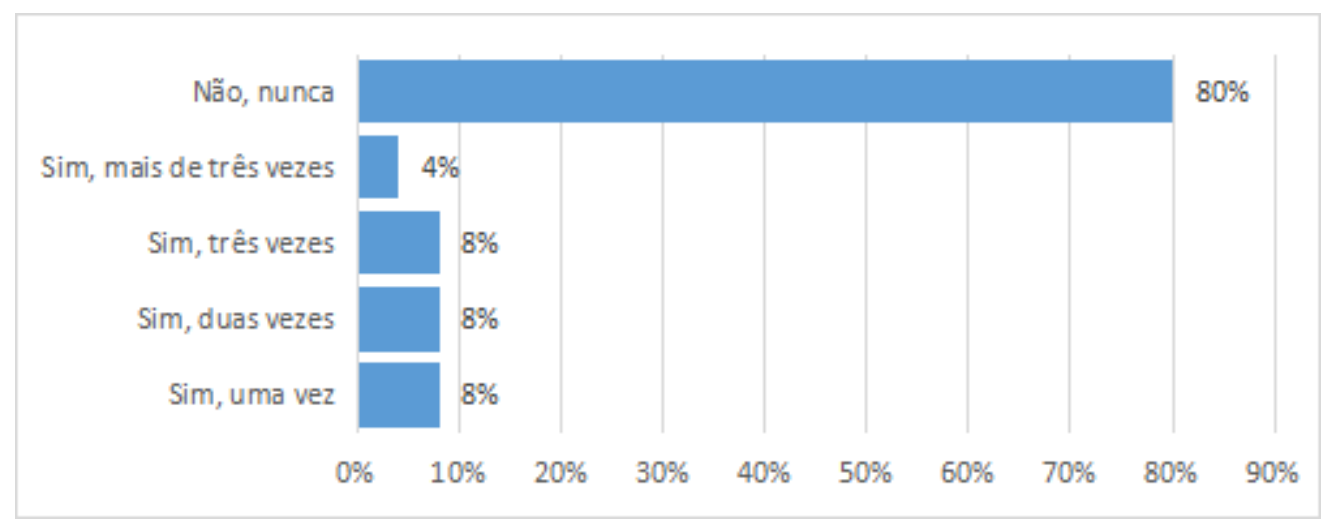

Fonte: Autoria própria

Nesta direção, a principal intuição é que a maioria nunca reprovou a disciplina e apenas 1 dos alunos que respondeu a pesquisa já cursou mais de 3 vezes a disciplina.

Para os discentes que obtiveram algum insucesso na componente curricular de Algoritmos, o principal fator indicado foi a falta de tempo para se dedicar à disciplina $(33,3 \%)$, como pode ser visto na Figura 9. 
Figura 9 - Motivos de trancar, desistir ou reprovar a disciplina

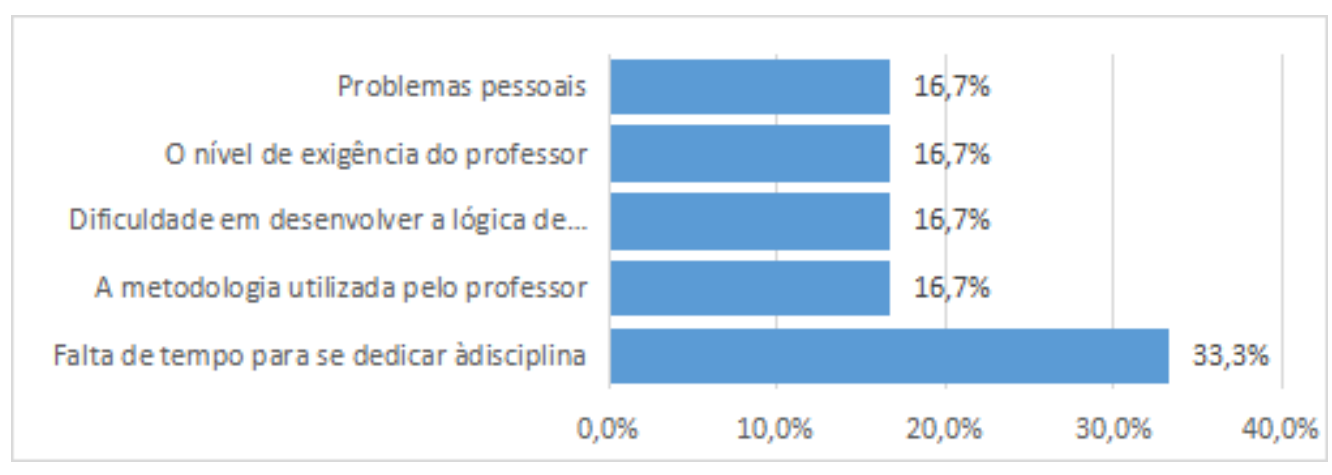

Fonte: Autoria própria

No entanto, identificou-se que, apesar das dificuldades apresentadas pelos discentes e da importância da componente curricular Algoritmos para o bom desempenho acadêmico no curso, apenas $40 \%$ dos discentes buscam conteúdos fora do rol disponibilizado pelo docente, conforme ilustrado na Figura 10. $\mathrm{Na}$ Tabela 4, são apresentados os principais comentários dos discentes no tocante a busca de conteúdos extras.

Figura 10 - Frequência de busca por conteúdos fora do que o professor passou nas aulas de Algoritmos

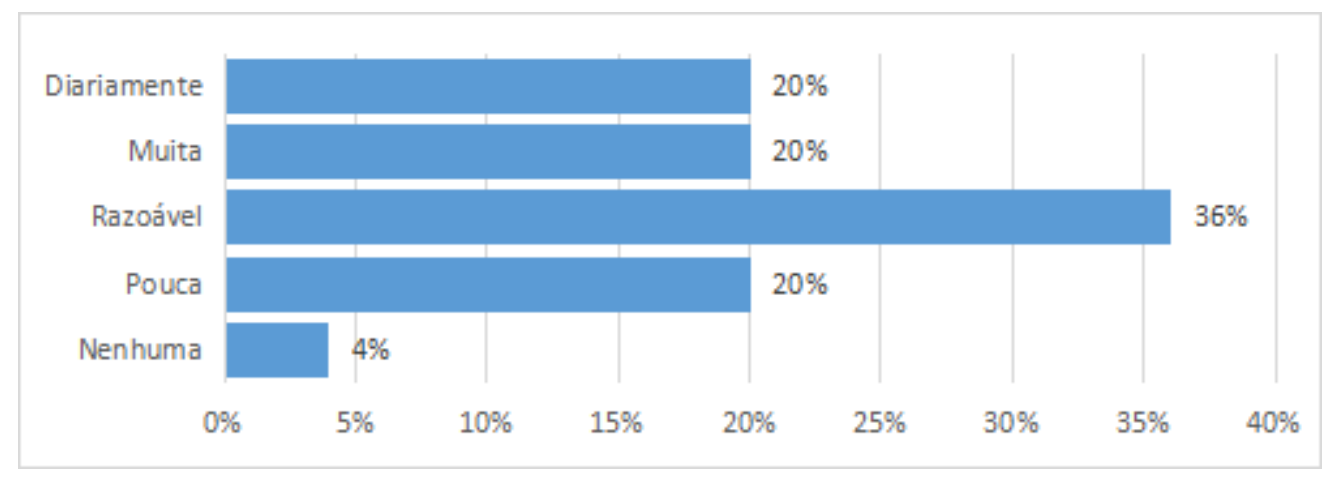

Fonte: Autoria própria 
Tabela 4 - Síntese dos principais comentários sobre a busca de conteúdos, além daqueles abordados na componente curricular

Procuro novas funções, novos códigos e novas formas de construir o código, o que me traz proficiência.

Um bom programador é um bom pesquisador.

Pesquiso informações sobre as linguagens em sites de desenvolvedores.

Conforme questionamentos anteriores, as principais intuições foram: (i) dos que repetiram a disciplina, a maioria foi por falta de tempo para se dedicar a disciplina e os demais devido às dificuldades relacionadas à metodologia ou nível de exigência do professor, dificuldades em compreender a sintaxe e a lógica da programação ou por problemas pessoais; e (ii) a maioria procura de forma razoável por conteúdos fora da sala de aula.

\section{Caracterização dos docentes}

No sentido de caracterizar os docentes, foram coletadas informações tais como gênero, idade e a quanto tempo leciona na UFERSA. Neste sentido, metade dos docentes são do sexo feminino e metado do sexo masculino. Além disso, metade dos docentes possuem entre 31 e 35 anos, outros $33,3 \%$ possuem entre 20 e 25 anos e $16,7 \%$ possuem entre 36 e 40 anos.

Os docentes em sua maioria apresentam mais de 5 anos na instituição (50\%). Os demais são recentes, entre 1 e 2 anos de instituição $(33,3 \%)$ e um ano de instituição $(16,7 \%)$. 


\section{Perspectiva dos docentes sobre o ensino de programação}

Os docentes possuem bastante experiência no ensino de Algoritmos, tendo em sua maioria lecionado a disciplina quatro ou mais vezes (50\%). Outros 33,3\% já ministraram a disciplina duas vezes e $16,7 \%$ já ministraram por três vezes, conforme pode ser visto na Figura 11 .

Figura 11 - Frequência que o docente ministrou a disciplina Algoritmos

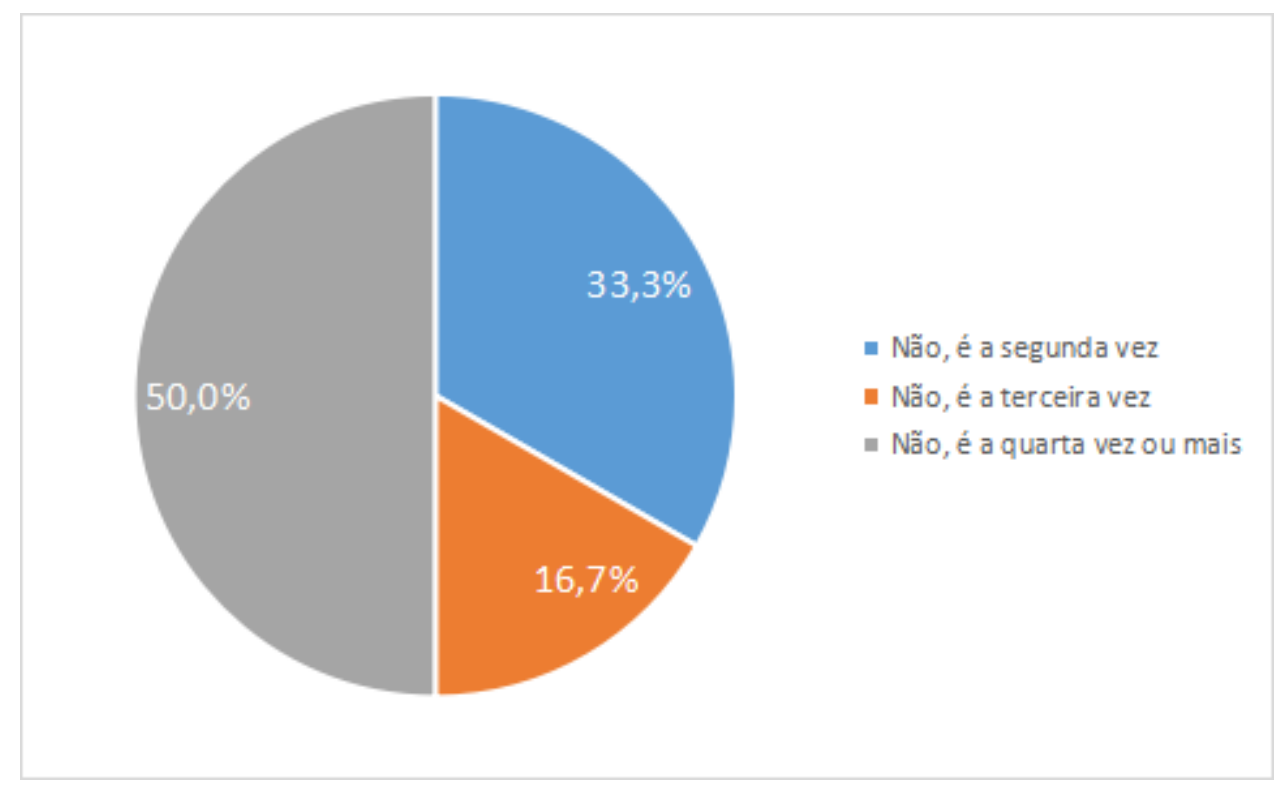

Fonte: Autoria própria

Assim como os discentes apontaram, as maiores dificuldades dos discentes, na visão dos docentes, estão associadas ao entendimento das estruturas de repetição $(83,3 \%)$, conforme visto na Figura 12. Em menor grau foi citado o tema de vetores, matrizes e strings $(16,7 \%)$.

Nos comentários adicionais foi apontado que as dificuldades iniciam com estruturas de repetição e se estendem para os demais conteúdos subsequentes, uma vez que dependem do bom entendimento do conceito de estruturas de repetição. 
Figura 12 - Conteúdos abordados que os alunos apresentaram maior dificuldade

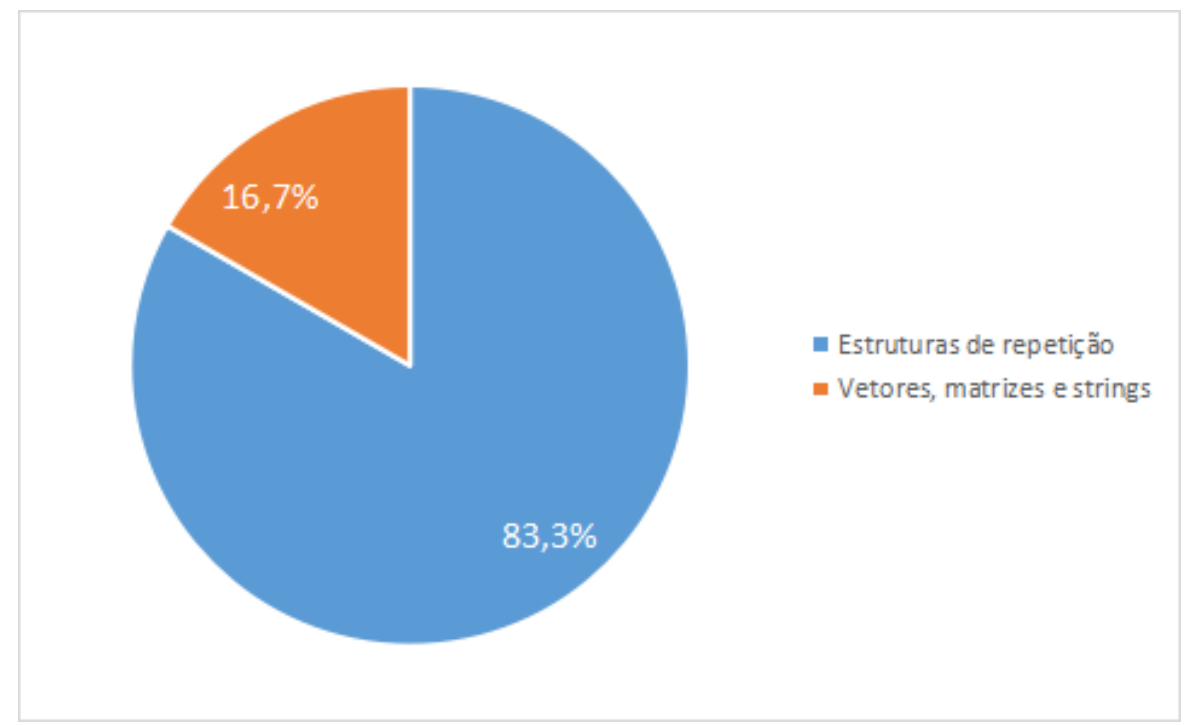

Fonte: Autoria própria

Neste sentido, como intuições principais tem-se que: (i) os professores observaram que a maior dificuldade dos alunos é em estruturas de repetição, seguido de vetores, matrizes e strings; e (ii) a dificuldade com estrutura de repetição está em conformidade com a informação dada pelos discentes.

$\mathrm{Na}$ visão dos docentes, os discentes apresentam participação insuficiente nas turmas, tendo apontado que $16,7 \%$ participam muito pouco, $33,3 \%$ participam pouco e apenas 2,8\% são neutros. Outros 33,3\% apontam que a participação dos discentes é mediana, conforme pode ser observado na Figura 13, em que são elencadas várias características associadas aos discentes.

Corroborando com o ponto anterior, identificou-se que a maioria dos docentes aponta que os discentes apresentam dificuldades de concentração (50\%). Ademais, foi pontuado pelos docentes que a procura dos discentes é muito baixa (50\%) ou baixa $(33,3 \%)$.

Por outro lado, foi identificado que o empenho dos discentes em sua maioria é mediano para resolver as atividades solicitadas (50\%). Outros 33,3\% apontaram que os discentes são empenhados e 16,7\% informaram que o empenho é baixo. 
Contrastando com as percepções anteriores, os docentes apontaram que a permanência dos discentes nas aulas do início ao fím é alto (50\%) ou muito alto (16,7\%).

Figura 12 - Conteúdos abordados que os alunos apresentaram maior dificuldade

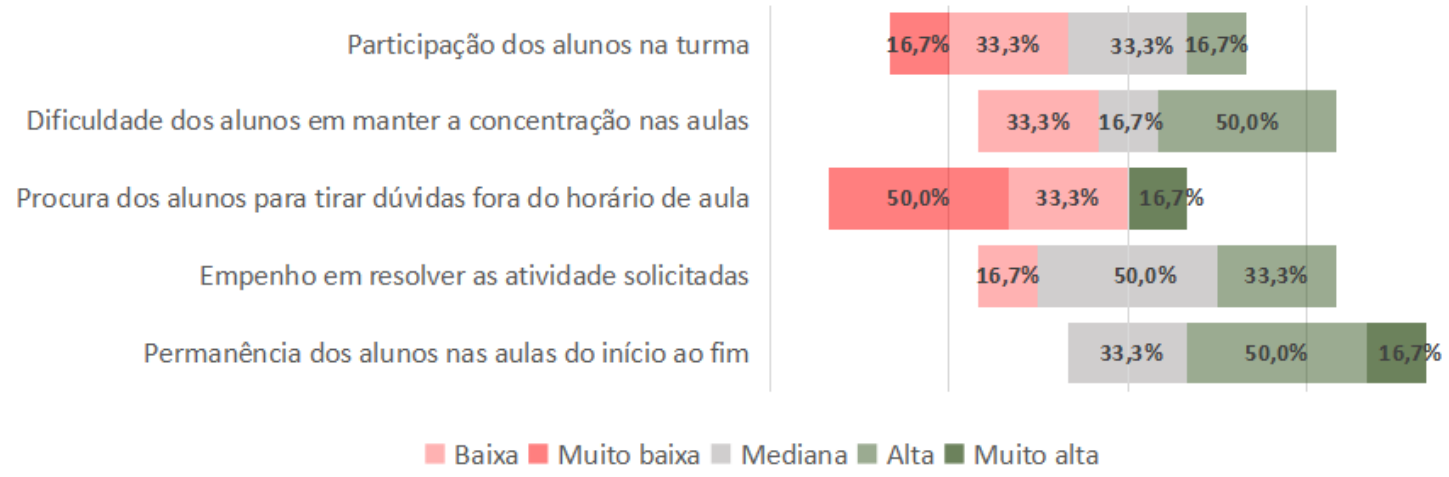

Fonte: Autoria própria

Como intuição principal da Figura 13, tem-se que os professores notaram uma baixa participação nas aulas, um alto nível de dificuldade em manter a concentração, uma baixa procura para tirar dúvidas bem como um esforço mediano dos alunos em resolver os exercícios propostos e uma alta permanência nas aulas.

O sentimento dos docentes é que o desempenho dos alunos é baixo (50\%) ou mediano (33,3\%). Apenas um docente caracterizou o desempenho como muito alto $(16,7 \%)$.

\section{CONCLUSÃO}

Nesta pesquisa, foi realizado um estudo para identificar as perspectivas dos discentes e docentes no tocante ao ensino-aprendizagem de programação. O estudo consistiu no desenvolvimento de dois surveys, um voltado para entender as perspectivas dos discentes sobre a temática e um segundo voltado a entender as percepções dos docentes sobre a temática. Os principais aspectos identificados no estudo foram que: (i) os alunos sentem mais dificuldade em estruturas de repetição; (ii) o estudo em grupo afetam positivamente o aprendizado dos discentes e as vídeo-aulas também ajudam o 
aluno a entender, por ser mais organizado e metódico; e (iii) analisando os dados dos professores, conclui-se que uma boa parcela dos alunos não se dedica tanto a disciplina.

Como trabalho futuro, pretende-se desenvolver uma plataforma para auxiliar no ensino de programação, que busca atender as necessidades apontadas neste estudo, a exemplo de um sistema para fornecer dicas ao longo da resolução dos problemas de programação e também iniciativas para atacar as dificuldades dos alunos com a lógica de programação e o tema estruturas de repetição.

\section{AGRADECIMENTOS}

Agradecemos ao grupo de pesquisa LIS - Laboratório de Inovações em Software, pelo apoio na produção deste trabalho, e à Universidade Federal Rural do Semi-Árido UFERSA pelo financiamento, por meio da Pró-Reitoria de Pesquisa e Pós-Graduação (PROPPG) através do Edital PROPPG N 12/2020 de Apoio a Grupos de Pesquisa.

\section{REFERÊNCIAS}

GOMES, A.J. Dificuldades de aprendizagem de programação de computadores: contributos para a sua compreensão e resolução. Coimbra: Universidade de Coimbra, 2010. 492p. Tese de Doutorado.

HOLANDA, W.D.; FREIRE, L.P.; COUTINHO, J.C.S. Estratégias de ensinoaprendizagem de programação introdutória no ensino superior: uma Revisão Sistemática da Literatura. Renote, [s.1.], v. 17, n. 1, p.527-536, 28 jul. 2019. Universidade Federal do Rio Grande do Sul.

HOLANDA, Wallace; COUTINHO, Jarbele; FONTES, Laysa. Uma Intervenção Metodológica para Auxiliar a Aprendizagem de Programação Introdutória: um estudo experimental. Anais dos Workshops do Congresso Brasileiro de Informática na Educação, [S.1.], p. 699, out. 2018. ISSN 2316-8889.

MOREIRA, G. L.; HOLANDA, W.; COUTINHO, J. C.; CHAGAS, F. S. Desafios na aprendizagem de programação introdutória em cursos de ti da UFERSA, campus Pau dos Ferros: um estudo exploratório. In Proceedings of the III Encontro de

Computação do Oeste Potiguar. ECOP '18, pages 90-96. 2018. 
MORRIS, Laura; CRUICKSHANK, Leon. New Design Processes for Knowledge Exchange Tools for the New IDEAS Project. In Proceedings of the Knowledge Exchange, CX '13, pages 1-6. 2013.

QUEIROZ, J. V.; RODRIGUES, L. M.; COUTINHO, J. C. Um relato dos fatores motivacionais na aprendizagem de programação na perspectiva de alunos iniciantes em programação da universidade federal rural do Semi-Árido campus Pau dos Ferros/RN. In Proceedings of the III Encontro de Computação do Oeste Potiguar. ECOP '18, pages 90-96. 2018.

SOUSA, R. R. Motivando os Discentes e Solucionando seus Desafios de Aprendizagem, um Estudo do Projeto de Ensino Pré-Algoritmos. V Encontro de Computação do Oeste Potiguar. ECOP'20. 2020a.

SANTOS, P. S. C.; ARAUJO, L. G. J; BITTENCOURT, R. A. A mapping study of computational thinking and programming in brazilian k-12 education. In Proceedings of the 2018 IEEE Frontiers in Education Conference. FIE'18, pages 1-8. 2018.

SOUSA, R. R., LEITE, F. T., GUIMARÃES, A. O., AND OLIVEIRA, A. R. Préalgoritmos - Ações de Apoio à Melhoria do Ensino de Graduação. Brazilian Journal of Development, 6 (3): 12625-12635. 2020 b. 